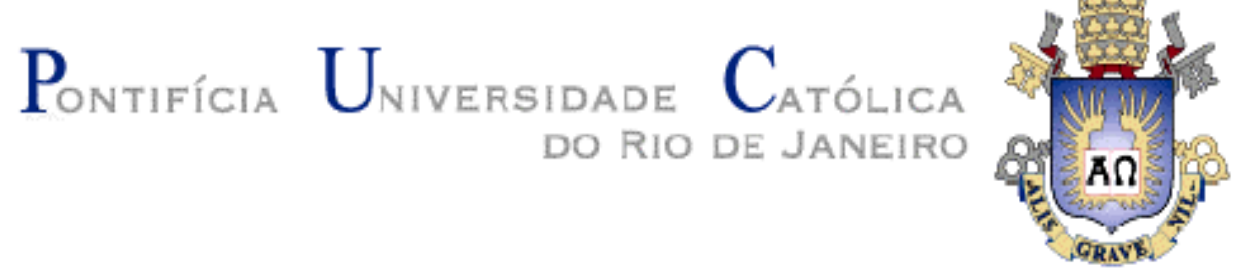

Diego Araujo de Lucena Henriques Lima

O Modelo de Gestão das Empresas do Grupo EBX: Uma Avaliação do Efetivo Alinhamento ao Planejamento Estratégico

Dissertação de Mestrado

Dissertação apresentada ao Programa de Pósgraduação em Administração de Empresas da PUCRio como requisito parcial para obtenção do título de Mestre em Administração de Empresas

Orientadora: Profa. Sandra Regina da Rocha Pinto

Rio de Janeiro

Novembro de 2011 
Diego Araujo de Lucena Henriques Lima

\section{O Modelo de Gestão das Empresas do Grupo EBX: Uma Avaliação do Efetivo Alinhamento ao Planejamento Estratégico}

Dissertação apresentada como requisito parcial para obtenção do grau de Mestre pelo Programa de Pósgraduação em Administração de Empresas da PUC-Rio. Aprovada pela Comissão Examinadora abaixo assinada.

Profa. Sandra Regina da Rocha Pinto

Orientadora

Departamento de Administração - PUC-Rio

Profa. Ana Heloisa da Costa Lemos Departamento de Administração - PUC-Rio

Prof ${ }^{a}$. Mônica Zaidan Gomes Rossi

FACC-UFRJ

Profa. Mônica Herz

Vice-Decana de Pós-Graduação do CCS

Rio de Janeiro, 30 de novembro de 2011 
Todos os direitos reservados. É proibida a reprodução total ou parcial do trabalho sem autorização da universidade, do autor e da orientadora.

\section{Diego Araujo de Lucena Henriques Lima}

Concluiu o $2^{\circ}$ grau no Colégio Marista São José do Rio de Janeiro e é graduado em administração de empresas pela PUC-RIO. Iniciou sua carreira na InfoGlobo Comunicações na área de Planejamento Logístico e Gerenciamento de Projetos. Trabalhou ainda na Vale, na implantação do modelo de serviços compartilhados do Brasil e também no Banco BBM, na implantação do Escritório de Projetos da área de BackOffice. Atualmente é responsável pela área de gestão do Centro de Recursos Compartilhados do Grupo EBX, tendo participado do projeto de implantação desde o seu início em Janeiro de 2010.

\section{Ficha Catalográfica}

Lima, Diego Araujo de Lucena Henriques

O modelo de gestão das empresas do Grupo EBX: uma avaliação do efetivo alinhamento ao planejamento estratégico / Diego Araujo de Lucena Henriques Lima ; orientadora: Sandra Regina da Rocha Pinto. - 2011.

78 f. : il. (color.) ; $30 \mathrm{~cm}$

Dissertação (mestrado)-Pontifícia

Universidade Católica do Rio de Janeiro, Departamento de Administração, 2011. Inclui bibliografia

1. Administração - Teses. 2. Planejamento estratégico. 3. Gestão de projetos. 4. Estratégia. I. Pinto, Sandra Regina da Rocha. II. Pontifícia Universidade Católica do Rio de Janeiro. Departamento de Administração. III. Título. 


\section{Agradecimentos}

A meus pais pela minha criação amável, pela paciência e oportunidades proporcionadas nesse mundo, além do apoio sempre presente nos momentos mais árduos da minha trajetória pessoal e profissional nesses 26 anos de vida. Saibam que esse documento é o símbolo da conclusão de mais uma etapa da minha vida, que sem vocês do meu lado nunca teria sido possível. Obrigado de coração, com todo amor do mundo.

Aos professores da PUC - Rio que compartilharam seus conhecimentos, e principalmente à Professora Sandra Regina da Rocha Pinto, por toda a orientação e convívio, desde os tempos de graduação até a conclusão desse Mestrado. Agradeço ainda a quem não está mais entre nós, ao querido professor José Roberto, que teria concluído em conjunto comigo esse trabalho e com quem dei os primeiros passos no nosso Mestrado Profissional e na troca de idéias que resultou nesse documento. 


\section{Resumo}

Lima, Diego Araújo de Lucena Henriques; Pinto, Sandra Regina da Rocha O modelo de gestão das empresas do Grupo EBX: uma avaliação do efetivo alinhamento ao planejamento estratégico. Rio de Janeiro, 2011. 78p. Dissertação de Mestrado - Departamento de Administração. Pontifícia Universidade Católica do Rio de Janeiro.

Este trabalho tem como objetivo abordar o modelo de gestão, a interação entre os conceitos de planejamento estratégico, gestão de projetos e portfólio e entender como essa interação ocorre nas empresas do Grupo EBX. Analisa, também, em que medida o gerenciamento reflete o direcionamento traçado no planejamento estratégico de cada empresa. Foram estabelecidas quatro proposições, que segundo a literatura estudada seriam os alicerces para o perfeito desdobramento da estratégia definida e os projetos gerenciados nas organizações: a) uma efetiva execução do planejamento estratégico de uma organização depende da qualidade da própria estratégia formulada; b) a organização deve seguir a estratégia e não o inverso; c) a estratégia deve envolver diretamente as pessoas; e d) a estratégia depende da implementação de iniciativas capazes de transformar a organização para os desafios futuros (melhoria de processos internos). Foram entrevistados oito executivos de diferentes empresas do Grupo EBX durante o primeiro semestre de 2011. A análise do conteúdo das entrevistas possibilitou a conclusão, juntamente com a literatura, da situação do Grupo EBX acerca do tema e de suas práticas de gestão da estratégia dos seus empreendimentos. O resultado da pesquisa sugere algumas ações a serem traçadas. A principal conclusão é a de que, a partir das proposições formuladas, a estratégia não foi efetivamente desdobrada para todos os níveis das empresas, tampouco suportada como deveria, gerando, em alguns casos, um desalinhamento entre os projetos gerenciados e o plano de negócios de cada empreendimento.

\section{Palavras-chave}

Planejamento Estratégico; Gestão de Projetos; Estratégia 


\section{Abstract}

Lima, Diego Araújo de Lucena Henriques; Pinto, Sandra Regina da Rocha (Advisor). Management Model in the EBX Group Companies: An Assessment with the Strategic planning. Rio de Janeiro, 2011. 78p. MSc. Dissertation - Departamento de Administração. Pontifícia Universidade Católica do Rio de Janeiro.

This work aims to address management model, the interaction between the concepts of strategic planning, project management and portfolio management and understand how this interaction occurs in the EBX Group organizations. It also analyzes how the management reflects the direction outlined in the strategic planning of each company. Four propositions were established for this paper, which according to the literature studied would be the perfect foundation for the unfolding of the strategy defined and project management in organizations: a) an effective implementation of the strategic planning of an organization depends on the quality of its strategy set, b) the organization should follow the strategy and not the reverse; c) the strategy must involve people directly, and d) the strategy depends on the implementation of initiatives to transform the organization for future challenges (improving internal processes). Interviews were done with eight executives from different companies of the EBX Group, during the first semester of 2011. The content analysis of the interviews allowed the conclusion, together with the literature, the situation of the EBX Group on the subject and its practical management strategy for their enterprises. The survey results suggest some actions to be traced. The main conclusion is that, from the propositions formulated, the strategy has not been effectively deployed to all levels of companies or supported as it should, leading in some cases, a misalignment between the managed projects and business plan of each enterprise.

\section{Keywords}

Strategic Planning; Project Management; Strategy 


\section{Sumário}

1. Introdução 9

1.1. Problema de Pesquisa $\quad 9$

1.2. Declaração do Estudo 10

1.3. Relevância do Estudo 11

1.4. Delimitação do Estudo 12

1.5. Limitação do Método 12

1.6. Organização da Dissertação 13

2. Referencial Teórico 15

2.1. Modelo de Gestão 15

2.2. Gestão de Projetos 15

2.3. Estratégia e Planejamento Estratégico 17

2.4. Gestão de Portfólio de Projetos e Planejamento Estratégico 20

2.5. Premissas para Avaliação do Alinhamento dos Projetos

Gerenciados com a Estratégia da Organização 25

3. Metodologia de Pesquisa 27

3.1. Apresentação da Metodologia 28

3.2. Estratégia e Justificativa $\quad 29$

3.3. Seleção de Sujeitos 30

3.4. O Procedimento de Coleta e Registro de Dados 30

3.5. Tratamento de Dados 31

3.6. Limitações do Método 32

4. Análise dos Resultados 33

4.1. Breve Descrição do Grupo EBX 33

4.2. Caracterização da Análise 34

4.3. Consolidação e Resultados

4.4. Análise das Declarações Relevantes 36

4.4.1. Gestão da Estratégia e Planejamento Estratégico 37

4.4.2. Processos e Estratégia 40

4.4.3. Estratégia e Pessoas 42

4.4.4. Estratégia e o Desenvolvimento Organizacional 44

5. Conclusão 46

5.1. Recomendações 48

5.2. Sugestões para Novas Pesquisas 49

6. Referências Bibliográficas $\quad 50$

7. Apêndices

7.1. Apêndice 1 - Roteiro de Entrevista 54

7.2. Apêndice 2 - Matrizes por Empresa das Percepções por

Proposição e Pergunta do Roteiro de Entrevista 57 


\section{Lista de figuras}

Figura 1: Planejamento Estratégico, Processos e Projetos

Figura 2: Contexto Organizacional - Desdobramento da Estratégia em Projetos

Figura 3: Relação dos entrevistados, com detalhamento por função, empresa e segmento de atuação

Figura 4: Matriz de Análise por Empresa (OSX) das Percepções

por Proposição e Pergunta do Roteiro de Entrevista

Figura 5: Relação de Interdependência entre as Quatro Categorias 